\title{
Revisitando o debate da violência, dos abusos e maus-tratos sofridos pela pessoa idosa
}

\section{Revisiting the debate on violence, abuse and mistreatment suffered by the elderly}

\author{
Maria Luiza de Andrade Picanço Meleiro ${ }^{1}$, Izaura Rodrigues \\ Nascimento $^{2}$, André Luiz Machado das $\mathrm{Neves}^{3}$
}

\begin{abstract}
Resumo
O Brasil passa por mudanças significativas e profundas em sua estrutura etária, com isso o contingente de idosos só tende a aumentar. Concomitante a esse aumento, crescem também, na mesma proporção, os desafios que o País tende a enfrentar face a estas transformações. Nesse aspecto, objetiva-se revisitar debates sobre maus-tratos e abusos sofridos pelas pessoas idosas e explorar a produtividade analítica do conceito de violência e demografia para se pensar a relação contemporânea. Para isso, realizouse uma pesquisa de revisão narrativa da literatura. Adotamos uma abordagem de cunho sociológico sobre o tema da violência. Para tal partiu-se de algumas ideias de Norbert Elias, Michel Foucault, Max Weber, Michel Misse, Willem Schinkel e Thomas Hobbes. Todos relacionam a violência ao poder, como Foucault, no entanto alguns se voltaram para o entendimento de sua fonte (Hobbes), configuração (Elias), para o Estado moderno que detém o monopólio legítimo de seu uso (Weber), outros para a compreensão sociológica contemporânea da violência na problemática que envolve estrutura e sujeito (Skinkel, Misse). Conclui-se que as várias formas de violência sofridas pelos idosos brasileiros constituem práticas sociais de violação de direitos consagrados na Constituição da República de 1988 e no Estatuto do Idoso. Portanto, é necessário resguardar e proteger os direitos dos idosos. Apesar das inúmeras possibilidades e contextos em que se originam, as várias expressões de violência podem ser devidamente tratadas, prevenidas e reduzidas.
\end{abstract}

Palavras-chave: Violência; Violência contra idosos; Envelhecimento populacional.

\footnotetext{
${ }^{1}$ Doutorado em Educação pela Universidad Católica de Santa Fe (UCSF), Santa Fe, Argentina. Mestrado em Segurança Pública, Direitos Humanos e Cidadania pela Universidade do Estado do Amazonas (UEA), Manaus, Amazonas, Brasil.

${ }^{2}$ Doutorado em Relações Internacionais e Desenvolvimento Regional pela Universidade de Brasília (UnB), Brasília, Distrito Federal, Brasil. Professora do Programa de Pós-graduação em Segurança Pública, Cidadania e Direitos Humanos (PPGSP) da Universidade do Estado do Amazonas, Manaus, Amazonas, Brasil.

${ }^{3}$ Doutorado em Saúde Coletiva pela Universidade Federal do Rio de Janeiro (UFRJ), Rio de Janeiro, Rio de Janeiro, Brasil. Professor do Programa de Pós-graduação em Segurança Pública, Cidadania e Direitos Humanos da Universidade do Estado do Amazonas, Manaus, Amazonas, Brasil.E-mail: andre_machadostm@hotmail.com
} 


\begin{abstract}
Brazil is going through significant and profound changes in its age structure, with this the contingent of elderly people only tends to increase. Concomitant to this increase, the challenges that the country tends to face in the face of these transformations also grow in the same proportion. In this aspect, the objective is to revisit debates about maltreatment and abuse suffered by the elderly and explore the analytical productivity of the concept of violence and demography in order to think about the contemporary relationship. In this sense, we adopt a sociological approach to the topic of violence. To this end, we started from some ideas of Norbert Elias, Michel Foucault, Max Weber, Michel Misse, Willem Schinkel and Thomas Hobbes. All relate violence to power, like Foucault, however some turned to the understanding of its source (Hobbes), configuration (Elias), to the modern State that holds a legitimate monopoly of its use (Weber), others to the understanding contemporary sociology of violence in the problematic that involves structure and subject (Skinkel, Misse). It is concluded that the various forms of violence suffered by elderly Brazilians constitute social practices that violate rights enshrined in the Constitution of the Republic of 1988 and in the Statute of the Elderly. Therefore, it is necessary to safeguard and protect the rights of the elderly. Despite the countless possibilities and contexts in which they originate, the various expressions of violence can be properly treated, prevented and reduced.
\end{abstract}

Keywords: Violence; Violence against the elderly; Population aging.

\section{Introdução}

A Constituição da República Federativa do Brasil de 1988 foi um marco rumo à conquista dos direitos sociais do povo brasileiro. Seu caráter cidadão teve como referência internacional a Declaração Universal dos Direitos Humanos, proclamada através de Resolução da Assembleia Geral das Nações Unidas em 10 de dezembro de 1948, e indica o respeito aos direitos e liberdades da pessoa humana como o ideal comum a ser atingido por todos os povos e todas as nações (ALCÂNTARA; CAMARANO; GIACOMIN, 2016). A cidadania e a dignidade da pessoa humana como fundamentos do Estado Democrático de Direito são os pilares que alicerçam a Constituição da República Federativa do Brasil (BRASIL, 1988).

Os direitos dos idosos não ficaram de fora do bojo constitucional. No Artigo 229, a Lei define que "os pais têm o dever de assistir, criar e educar os filhos menores, e os filhos maiores têm o dever de ajudar e amparar os pais na velhice e, carência ou enfermidade". E na sequência, o Artigo 230 estabelece que a família, a sociedade e o Estado têm o dever de amparar as pessoas idosas, assegurando sua participação na comunidade, defendendo sua dignidade e bem-estar e garantindo-lhes o direito à vida.
Em 4 de janeiro de 1994 foi promulgada a Política Nacional do Idoso (Lei ${ }^{\circ} 8.842 / 1994$ ), com o objetivo principal de assegurar os direitos sociais do idoso, criando condições para promover sua autonomia, integração e participação efetiva na sociedade (BRASIL, 1994). Contudo, o mais esperado e festejado arcabouço jurídico direcionado à população idosa brasileira foi, sem dúvida, a promulgação do Estatuto do Idoso (Lei $n^{0} 10.741 / 2003$ ) (BRASIL, 2003). Com o compromisso de fomentar, garantir e promover os direitos da pessoa idosa com o envelhecimento ativo e saudável, dignidade, independência, protagonismo e autonomia, o Estatuto do Idoso representa um marco jurídico para a proteção da população idosa brasileira.

Após a visibilidade constatada a partir dos índices de violência e maus-tratos sofridos pelos idosos brasileiros, em 2011, foi promulgada a Lei $\mathrm{n}^{\circ}$ 12.461/11 (BRASIL, 2011), que reformula o artigo $\mathrm{n}^{\circ} 19$ do Estatuto do Idoso (Lei $\mathrm{n}^{\circ} 10.741 / 03$ ), tornando obrigatória a notificação por parte dos profissionais de saúde, às autoridades sanitárias, Ministério Público, autoridade policial, conselhos Municipal, Estadual e Nacional do Idoso, em caso de suspeitas ou confirmação de violências contra os idosos. 
Percebe-se, dessa forma, que o Estado brasileiro possui um arcabouço legal alinhado às exigências e tratados internacionais que objetivam dar proteção ao idoso e resguardar os seus direitos fundamentais. Porém, estudos apontam que esses direitos são lesados e em muitos casos os idosos são violentados de forma cruel, e às vezes, até letal (SOUSA LOPES; D'ELBOUX, 2021; SOUSA et al., 2021).

Apoiado em pesquisa bibliográfica e em documentos oficiais do governo brasileiro, foi realizada pesquisa de revisão narrativa da literatura. A base desse artigo é o método dialético como a lente orientadora de todo o processo de pesquisa e de análise realizado. De acordo com Lima e Mioto (2007), o método dialético pode possibilitar a contradição e o conflito; as descobertas no caminho da pesquisa; o movimento histórico; além de apreender, em todo o percurso de pesquisa, as dimensões filosófica, material/concreta e política que envolvem a violência contra a pessoa idosa. A opção pela perspectiva dialética se deu por ela pontuar as diferenças paradigmáticas entre esse método e o de outras teorias do conhecimento, pois a nenhuma linha de pensamento, ou método, cabe o monopólio da apreensão e explicação total e completa da realidade social (LIMA; MIOTO, 2007).

Frente a essas premissas, este artigo objetiva revisitar debates sobre maus-tratos e abusos sofridos pelas pessoas idosas e explorar a produtividade analítica do conceito de violência e demografia para se pensar a relação contemporânea.

\section{A nova era demográfica}

Uma das maiores conquistas culturais de um povo em seu processo de humanização é o envelhecimento de sua população, que reflete uma melhoria das condições de vida, nos seus mais variados aspectos. De acordo com projeções do Fundo de Populações, órgão ligado às Nações Unidas, uma em cada nove pessoas no mundo tem 60 anos ou mais, e estima-se um crescimento para um em cada cinco por volta de 2050 , ou seja, passará de $11 \%$ para $20 \%$, duplicando sua população. Em 2050 também será o ano em que pela primeira vez haverá mais idosos que crianças menores de 15 anos no planeta. Projeta-se que o número de idosos alcance 1 bilhão por volta do ano de 2022 e mais que duplique em 2050, alcançando 2 bilhões de pessoas ou 22\% da população global (PNUD, 2017).

Estudos da Comissão Econômica para a América Latina e Caribe (CEPAL) apontam que o comportamento demográfico na América Latina e no Caribe, ao mesmo tempo em que se alinha e converge com outras regiões do mundo, possui características particulares que o distingue. Tais características são frutos do momento em que se iniciaram as transições demográfica, epidemiológica e urbana de seus países; a velocidade em que isso ocorreu; a diversidade de situações entre e dentro deles; e, especialmente, o contexto de heterogeneidade estrutural e sua principal consequência no plano social. Tal estudo prevê que o número de habitantes na América Latina e no Caribe irá aumentar de 512 milhões de pessoas no ano 2000, para 734 milhões de pessoas em 2050 (CEPAL, 2014).

A magnitude e a velocidade dos câmbios populacionais pelos quais a América Latina e o Caribe têm experimentado nos últimos anos são de tal envergadura que a División de Población do Centro Latinoamericano y Caribeño de Demografía (CELADE) chegou a denominar de "nueva era demográfica": passando de intenso crescimento populacional na segunda metade do século XX, para projeções que apontam modificações na estrutura por idade da população, com o avanço crescente e profundo do processo de envelhecimento em todos os países, já na primeira metade do século XXI, ou seja, a América Latina e o Caribe passarão do boom demográfico para as sociedades envelhecidas ${ }^{4}$, com todas as implicações e desafios que esta realidade traz consigo (CELADE, 2014).

\footnotetext{
${ }^{4}$ Sociedades envelhecidas - conforme a Organização Mundial da Saúde (OMS), essa classificação é dada aos países com mais de $14 \%$ da população constituída de idosos, como são, atualmente, França, Inglaterra e Canadá, por exemplo.
} 
Tais mudanças são resultantes principalmente da redução das taxas de fecundidade e do aumento da longevidade. A taxa de fecundidade na América Latina e no Caribe era uma das mais altas do mundo, com cerca de seis filhos por mulher entre 1950 e 1955. Em 2015, a taxa já era de 2,2 filhos por mulher, índice abaixo da média mundial $(2,3)$. Já a expectativa de vida na região entre 1950 e 1955 era de 55,7 anos, dez anos a menos que a média dos países desenvolvidos. Entre 2010 e 2015, essa cifra subiu para 74,7 anos, um aumento que se deve em grande parte à redução da mortalidade infantil e das políticas sociais voltadas para os idosos (CELADE, 2014).

De acordo com o estudo de Camargos et al. (2019), aponta-se que entre 1998 e 2013, concomitantemente aos ganhos na expectativa de vida no Brasil, ocorreu um crescimento na expectativa de vida livre de incapacidade funcional. Por outro lado, os ganhos na expectativa de vida livre de incapacidade funcional não foram estatisticamente significativos para as regiões Norte e Centro-Oeste. Com exceção dessas regiões, além de viver mais, a população idosa de 60 anos poderia esperar viver um número maior de anos com saúde.

No Brasil, a mudança na demografia ocorre de forma ainda mais acentuada. De acordo com o Relatório Mundial de Saúde e Envelhecimento da Organização Mundial da Saúde (OMS), o número de pessoas com mais de 60 anos no País deverá crescer muito mais rápido do que a média internacional. Enquanto a quantidade de idosos vai duplicar no mundo até o ano de 2050, esta quase triplicará no Brasil. A porcentagem atual, de 12\% de idosos, deve alcançar os $30 \%$ até a metade do século. Ou seja, logo seremos considerados uma nação envelhecida, de acordo com a classificação da Organização Mundial da Saúde (OMS, 2015).

Em um levantamento e projeções realizados pela Comisión Económica para América Latina y el Caribe - CEPAL (2018) no final do ano de 2017, estima-se que as pessoas idosas ${ }^{5}$, entre 2015 e
2040, na América Latina e no Caribe aumentarão em quase 87 milhões de pessoas. E a população de 20 a 59 anos em quase 63 milhões de pessoas. Já a população com menos de 20 anos sofrerá uma redução de 26 milhões de pessoas em 2040 em relação a 2015. Respectivamente, as pessoas idosas registrariam taxas de crescimento muito elevadas. Prevê-se que a população de pessoas de 60 anos ou mais na América Latina e no Caribe aumentará à razão de 3,4\% ao ano no período 2015-2040, muito mais rapidamente do que a população de 20 a 59 anos, que cresceria $0,5 \%$ ao ano, e do que a população de menores de 20 anos, que diminuiria $0,5 \%$ ao ano.

Apesar dos esforços, a situação demográfica do Brasil aponta para um agravamento ainda maior. As mudanças na estrutura etária da população afetam as economias na medida em que alteram a distribuição das pessoas em idades de maior e menor produtividade laboral em comparação com seu consumo. Já em 2032, segundo a CEPAL, a população com mais de 60 anos será maior que a de 0 a 14 anos e o contingente de idosos tende somente a aumentar, trazendo sérias consequências, porquanto à medida que a distribuição etária da população se torna mais concentrada nas idades mais velhas o coeficiente de apoio econômico ${ }^{6}$ cai acentuadamente, representando crescentes desafios econômicos e fiscais para o Brasil.

O estudo da Organização das Nações Unidas (ONU) anteriormente citado, alerta aos países latino-americanos sobre os novos desafios no futuro muito próximo, por conta do envelhecimento populacional, e as medidas a serem tomadas, que dependerão em grande parte tanto do nível macroeconômico, - por meio de regimes de transformação produtiva e de tributação progressiva -, como do nível político, por meio de uma melhor educação e proteção social (ONU, 1999).

Partindo do estado em que residimos, lançamos mão do Amazonas, Unidade da Federação onde a população acima de 60 anos cresceu mais

${ }^{5}$ População idosa - a partir de 60 anos (BRASIL, 2003).

${ }^{6}$ Coeficiente de apoio econômico - relação entre população produtora/população consumidora. 
que a de crianças e adultos em dez anos. Segundo a Síntese de Indicadores Sociais (SIS) do Instituto Brasileiro de Geografia e Estatística (IBGE), o número de idosos no estado subiu 3,5\% desde 2005. Conforme o levantamento realizado no ano de 2017, eles são 8,8\% da população atual, mais de 347 mil idosos. Enquanto a população idosa cresceu, a de crianças e adolescentes diminuiu proporcionalmente. Os dados apontam que a população de 0 a 17 anos passou de 40,4\% em 2005 para 34,8\% em 2015 no estado do Amazonas (IBGE, 2017).

$\mathrm{O}$ fato é que o envelhecimento populacional é uma realidade em todos os países, em maior ou menor grau, e não obstante às medidas necessárias de enfrentamento que deverão estar na pauta de todos os gestores, no que dizem respeito ao equilíbrio econômico e fiscal. Se o nosso objetivo é viver com qualidade, é fundamental participar da reflexão e do debate de todas as questões que envolvem o envelhecimento. Isto é, ocorrer por meio do fortalecimento das pautas sobre empregabilidade, educação, saúde, sexualidade, assistência social, prevenção da violência etc.

Uma das questões que se quer debater diz respeito à defesa dos plenos direitos conquistados pelos idosos. E nesse contexto, a violência e maustratos sofridos por eles têm se manifestado como grave forma de violação aos seus direitos, tratandose, portanto, de um fenômeno social abrangente, às vezes difuso, cuja conscientização social é unânime em qualificar essa violência como um atentado aos direitos humanos.

Antes que se adentre especificamente na temática da violência contra os idosos, façamos breve análise sobre a violência como problema social.

\section{A violência como problema social}

Segundo Minayo, Souza e Paula (2010), o termo violência é de origem latina, vem da palavra vis, que quer dizer força e se refere às noções de constrangimento e de uso da superioridade física sobre o outro. No seu sentido material, o termo parece neutro, mas quem analisa os eventos violentos descobre que eles se referem a conflitos de autoridade, a lutas pelo poder e à vontade de domínio, de posse e de aniquilamento do outro ou de seus bens.

Para as mesmas autoras, encerrar a noção de violência numa definição fixa e simples é expôrse a reduzi-la, a compreender mal sua evolução e sua especificidade histórica, uma vez que possui um caráter mutante. Nesse sentido a violência designa, pois - de acordo com épocas, locais e circunstâncias - realidades muito diferentes. Da mesma forma, Nilo Odália (2017, p. 15) assevera: “a violência não é o apanágio de uma época". E continua: "O viver em sociedade foi sempre um viver violento. Por mais que recuemos no tempo, a violência está sempre presente, ela sempre aparece em suas várias faces" (Idem, p. 13).

A maior parte das dificuldades para conceituar a violência vem do fato desta ser um fenômeno da ordem do vivido, cujas manifestações provocam ou são provocadas por uma forte carga emocional de quem a comete, de quem a sofre e de quem a presencia. Os eventos violentos sempre passaram e passam pelo julgamento moral da sociedade.

Santos (2004, p. 8) assinala que somente nos anos 1990 a temática da violência veio a "tornarse um problema social e uma questão sociológica no estado brasileiro". Diversos estudos produzidos principalmente por Bretas (1991), ao realizar uma revisão na pesquisa recente do crime na historiografia brasileira; Adorno (1993), ao abordar um recorte temático da criminalidade urbana violenta; Zaluar (1999), quanto traz suas concepções sobre violência e crime; Sposito (2001), ao sintetizar um balanço da pesquisa sobre violência escolar no Brasil; e Lima, Misse e Miranda (2000), quando realizam uma bibliografia da violência, criminalidade, segurança pública e justiça criminal no Brasil.

A partir dessa/es autora/es buscamos dar ênfase para alguns clássicos dos estudos sociológicos sobre crime, violência, polícias, poder judiciário, fenômenos da violência na escola e segurança pública. Tais estudos também propiciaram, em razão de sua diversidade regional, mapear e comparar 
cidades e estados, acrescendo a visibilidade social e a compreensão sociológica das conflitualidades na sociedade brasileira (SANTOS, 2004).

Ao abordar o tema da violência e dilemas do controle social nas sociedades da "modernidade tardia", Santos (2004) assevera que o Brasil do século XXI está vivendo num contexto de violência difusa. Tal fenômeno é, em larga medida, legitimada pela consciência coletiva, instituindo-se como norma social, ainda que controversa e polêmica. A ideia de violência difusa, conforme salientado pelo autor, contrapõe-se ao conceito de violência do sociólogo francês Émile Durkheim (1858-1917). Durkheim considera o crime um fenômeno social normal, uma vez que em toda a sociedade um certo número de crimes é cometido e, por consequência, se nos referimos ao que se passa regularmente, o crime não é um fenômeno patológico. Ainda assim, o crime é considerado por Durkheim uma ruptura com a consciência coletiva, razão pela qual sofre punição pela lei penal (ARON, 1967, p. 340).

O sociólogo francês Michel Wieviorka (1946), reconhecido por seus trabalhos com a temática da violência, em entrevista concedida na cidade do México no ano de 2018 considerou que, para abordar o tema da violência há a necessidade de tomar em conta os processos de objetivação e subjetivação dos sujeitos considerados violentos, a perda dos sentidos, sua reconstrução, sua ideologia, sua religião e assim por diante. Wieviorka se posiciona dentro de uma tradição antiestruturalista, que estabelece uma ideia de relação de condicionamento recíproco entre sentido e sujeito: o sujeito produz sentido e o sentido produz sujeito, numa relação biunívoca. Assinala que a violência hoje já é um tema bastante conhecido pelas Ciências Sociais, e coube a ela a exitosa tarefa da sua problematização. Contudo, a saída da violência não deve ser uma missão atribuída às Ciências Sociais e sim aos diversos atores como experts, planejadores, médicos, psiquiatras, psicanalistas, dentre outros intelectuais (WIEVIORKA, 2018).

Em outra entrevista concedida no Rio de Janeiro ao professor da UFRJ, Michel Misse, e outros sociólogos, no ano de 2009, Wieviorka afirmou que uma definição objetiva para a violência é impossível, porque o que seria violento para um sujeito, para um país, não seria para o outro. $\mathrm{O}$ que seria violento para a sociedade brasileira hoje, talvez não seja mais em 30 anos, e o que será violento daqui a 30 anos talvez não seja o que era violento hoje em nossas concepções. Para ele, passamos o tempo relativizando a violência. $\mathrm{O}$ que temos de forma permanente é o sentimento de que a violência é relativa (MISSE et al., 2009).

Mas se a violência é unicamente relativa, ou seja, se ela fosse unicamente produto da subjetividade individual ou coletiva, então não poderíamos discuti-la, analisá-la. Se um diz "isso é violento" e o outro "não, não é violento", então, não podem discutir o problema. E, consequentemente, o relativismo puro é inaceitável. Então, como fazer quando uma definição objetiva é tão difícil de ser encontrada e uma definição subjetiva ou relativista é inaceitável? É preciso encontrar acomodações, é preciso negociar consigo mesmo, circular, ter muita flexibilidade e não impedir a reflexão. Então é preciso que se encontre alguma coisa que se permita introduzir uma objetividade determinada, sempre deixando um certo espaço à relatividade. É difícil, mas não é impossível, segundo ele. É, no entanto, um problema real (MISSE et al., 2009).

Na mesma entrevista, Wieviorka é enfático ao afirmar que é possível se opor à violência sem violência. Considera que há as pessoas que teorizaram essa ideia, como Mohandas Karamchand Gandhi e todos aqueles que dizem que não é necessário ser violento. É uma primeira resposta. A segunda resposta não é se opor à violência pela não violência, mas se opor à violência dizendo que um só ator tem o seu monopólio legítimo, o Estado.

É, de certa forma, a resposta do teórico, político e filósofo inglês Thomas Hobbes (15881679), que na obra Leviatã (1651), defende a tese inspirada em uma figura mitológica, que é uma serpente que fez um acordo com os homens. Nela explanou os seus pontos de vista sobre a natureza humana e sobre a necessidade de um governo e de 
uma sociedade fortes. Thomas Hobbes considerava que a natureza humana é má e defendia a ideia segundo a qual os homens só podem viver em paz se concordarem em submeter-se a um poder absoluto e centralizado. $\mathrm{O}$ Estado não pode estar sujeito às leis por ele criadas pois isso seria infringir sua soberania (HOBBES, 2003).

Já para o sociólogo alemão Norbert Elias (1897-1990), há necessidade de distinguir natureza e cultura e todas essas questões fazem parte do que ele denominou de processo civilizatório. Elias (1990) demonstrou como os padrões europeus pósmedievais de violência, comportamento sexual, funções corporais, etiqueta à mesa e formas de discurso foram gradualmente transformados pelo crescente domínio da vergonha e do nojo, atuando para fora de um núcleo cortesão de etiqueta. $\mathrm{O}$ autocontrole era cada vez mais imposto por uma rede complexa de conexões sociais desenvolvidas por uma autopercepção psicológica, que o criador da psicanálise Sigmund Freud (1856-1939) cunhou como "superego". O segundo volume de O processo civilizatório aborda as causas destes processos e os reconhece nas cada vez mais centralizadas e diferenciadas interconexões na sociedade (ELIAS, 1993).

Elias realizou um aprofundamento histórico, ou seja, resgatou a história de uma palavra - civilidade -, do francês "civilité", para compreender os padrões de comportamento e da expressão de sensibilidade e emoções da sociedade ocidental. Neste retrocesso ele encontra a origem da palavra em um tradado do teólogo e humanista neerlandês Erasmo de Roterdã (1466-1536), de 1530, com o título “ $D a$ civilidade para crianças", que versa como alguém civilizado deveria se comportar nas mais diversas ocasiões. A ideia de Erasmo de Roterdã era transmitir alguns valores e comportamentos designados como civilizados para separar esses daqueles chamados de bárbaros ou incivilizados. Segundo Elias, esse texto ganhou força e notoriedade que a palavra civilité foi traduzida para outras línguas. Logo, ser civilizado passou a significar ter autorregulação e saber controlar seus impulsos (ELIAS, 1990, p. 65).

Considera Norbert Elias que a sociedade ocidental, através da nobreza e do cristianismo, foi fundada nesses pilares de civilização. Todo o indivíduo que não se comporta de certa forma é visto como incivilizado (ELIAS, 1990, p. 66).

Ao fazer esse resgate das emoções humanas, Elias faz o que se considera uma sociologia histórica, ou seja, uma sociologia de longa duração, pois procura no passado as origens do comportamento no presente. Isso só se faz possível por conta de um outro conceito de Norbert Elias, o de figuração ou configuração. Ele considera que tudo acontece através de um processo social. Nada está pronto e nada surge do nada. Tudo o que percebemos na sociedade é originário de um processo social. Ao pensar desse modo, conseguimos nos distanciar um pouco do momento presente e temos a possibilidade de vasculhar ao longo da história como chegamos aqui. $\mathrm{O}$ presente condena, no passado, a violência; mas, como afirma Elias, sem a violência o processo civilizador não teria existido: "Sem ações violentas, sem as forças propulsoras da livre competição, não teria havido monopólio de força e, destarte, nenhuma pacificação, nenhuma supressão e controle da violência em grandes áreas" (ELIAS, 1993, p. 139).

Elias chama a atenção para o fato de que todo esse processo só se torna importante quando acreditamos que não existe um indivíduo isolado, e tampouco uma sociedade centralizadora. O que existe, para ele, é uma figuração ou configuração social. Segundo Elias, a sociedade é uma figuração constituída de números indivíduos fundamentalmente interdependentes, ou seja, tributários dependentes uns dos outros. Pensar através da noção de configuração é perceber o indivíduo como alguém, cujas margens de manobra são limitadas porque

\footnotetext{
${ }^{7}$ Superego é o aspecto moral da personalidade do indivíduo, conforme a Teoria da Psicanálise de Sigmund Freud. O superego é responsável por "domar" o Id, ou seja, reprimir os instintos primitivos com base nos valores morais e culturais.
} 
vive com muitas outras pessoas, que também têm necessidades, estabelecem objetivos e tomam decisões. Ou seja, a ação de um indivíduo está sempre limitada pela ação do outro.

Semelhante à forma como Michel Foucault (1926-1984) ${ }^{8}$ e Max Weber (1864-1920) ${ }^{9}$ entendem o poder, Elias trabalha-o como algo que não se possui, mas que tem concretude. Entretanto, o exercício de poder, em Elias, pressupõe o controle preponderante de um grupo social sobre coisas, objetos e/ou pessoas. Portanto, em Elias, "o conceito de poder deixou de ser uma substância para se transformar numa relação entre duas ou mais pessoas e objetos naturais; assim, o poder é um atributo destas relações que se mantêm num equilíbrio instável de forças" (SALLAS, 2001, p. 219).

Assim tomado, o poder advém basicamente das relações humanas as mais variadas, e, com isso, ele pode assumir diversas formas. Como consequência, temos grupos sociais ou pessoas que podem reter ou monopolizar aquilo que os outros necessitam, como, por exemplo, comida, amor, segurança, conhecimento etc. (ELIAS, 1994). Desta forma, Elias (1994) amplia a noção de poder, para além da visão estatal ou econômica, vez que não a reduz às relações entre senhores e servos, dominadores e dominados, mas a estende nas que podem ocorrer entre indivíduos de uma mesma família, entre membros de bairros vizinhos.

Norbert Elias (1994) ressalta que a civilização, enquanto processo, conta com mecanismos de controle da violência e com a própria violência para exercê-los. Conquanto, estas três esferas (processo civilizatório, controle e violência) estão interligadas e coabitam numa perspectiva relacional. Desse modo, Elias identifica “o padrão de hábitos e comportamento a que a sociedade, em uma dada época, procurou acostumar o indivíduo" (Idem, p. 95).
Desta feita, a mudança de comportamento não está influenciada por questões de ordem científica, religiosa ou de higiene, a mudança de comportamento é uma consequência social, verificada porque "a estrutura alterada da nova classe expõe cada indivíduo [...] às pressões dos demais e do controle social" (ELIAS, 1994, p. 91).

O sociólogo e professor brasileiro Michel Misse é um dos estudiosos que se dedica aos estudos da violência. Ao abordar o tema da violência e teoria social, Misse (2016) é enfático ao afirmar que a "violência" é uma palavra moderna, cujo significado difere, em toda a sua extensão semântica, do que significava antes de começos do século XX, e que, na verdade, o sentido da palavra não só não deve ser encontrado antes da modernidade como se acha ainda em plena construção. Para ele há uma escassez teórica nos usos da violência nos discursos sociológicos contemporâneos e questiona os porquês de a violência não ter se tornado um dos tópicos mais importantes da teoria social até agora (MISSE, 2016).

Na tentativa de elaborar uma compreensão sociológica para o termo "violência", Misse considera que a violência não era um conceito e dificilmente viria a sê-lo, uma vez que trata-se de uma categoria que, deixando de ser meramente constatativa, torna-se necessariamente performática, normativa e acusatorial. Afirma Misse:

O uso da palavra acusa um acontecimento e no mesmo ato reclama-lhe uma ação contrária. Se o uso propõe a ação violenta, logo uma justificativa lhe é cobrada. Na modernidade, ninguém pode gostar da violência: é um anátema para quem a elogia ou para quem busca apenas compreendê-la, sem condená-la. Por recobrir um sentido negativo, sua polissemia potencializa a impossibilidade de contê-la em um enunciado do tipo constatativo (MISSE, 2016, p. 47).

\footnotetext{
${ }^{8}$ Para Michel Foucault não existe o poder, mas sim relações de poder, que através de seus mecanismos atuam como uma força coagindo, disciplinando e controlando os indivíduos. Considera que na modernidade, à medida em que foram mudando as relações sociopolíticas e econômicas, também foram sendo produzidas novas relações de poder, mais adequadas às necessidades do poder dominante (FOUCAULT, 1979).

${ }^{9}$ Max Weber (1991, p. 33) apresenta um clássico conceito de poder ao asseverar que: "poder significa toda probabilidade de impor a vontade numa relação social, mesmo contra resistências, seja qual for o fundamento dessa probabilidade". Ou melhor, é a probabilidade de que uma ordem com um determinado conteúdo específico seja seguida por um dado grupo de pessoas.
} 
Uma vez que o tema sempre fora abordado de forma negativa e contrafactual, não surpreende, segundo Misse, a ausência da violência como um dos tópicos centrais da teoria social no século XX. Contudo, nos últimos anos um crescente investimento teórico vem sendo realizado para constituir a violência como objeto digno da teoria social. E nesse sentido, Misse inclui seus esforços na tentativa de problematizar a possibilidade teórica de uma sociologia ou de uma antropologia da violência que enfrentem a complexidade conceitual do termo (MISSE, 2016, p. 49).

O sociólogo neerlandês Willem Schinkel (1976), autor de um dos mais importantes estudos da violência na atualidade, ao trabalhar com o conceito de violência, a define como uma redução do ser, ou seja, a redução de uma pessoa a apenas um de seus aspectos entre tantos outros desdobramentos possíveis em uma dada situação; as alternativas são inúmeras, mas a ação violenta direcionada a essa pessoa reduz e limita o espectro de possibilidades, em que a situação desdobra-se em apenas um resultado possível.

A violência a uma pessoa idosa, por sua vez, estaria por reduzir as possibilidades de ser da pessoa idosa. Quando certos valores morais, estéticos e também simbólicos são considerados como legítimos e como padrões os quais toda a sociedade deve seguir, temos um caso de violência simbólica, onde o idoso é obrigado a sentir vergonha de si e renunciar a valores que não se encaixam no padrão hegemônico, causando assim baixa autoestima e sentimentos de inferioridade e incapacidade (SCHINKEL, 2010).

Michel Misse, ao referir-se a esse autor, salienta os paradoxos contidos nos variados usos do termo "violência" nas Ciências Sociais:

A violência rompe com a ordem social ou a violência é constitutiva da ordem social? A violência é um problema social ou a violência é uma solução padronizada para os problemas sociais? A violência é uma forma puramente destrutiva da socialidade ou a violência é uma forma positiva de socialidade que faz as pessoas se unirem? Violência é uma forma de lidar com a contingência ou a violência é uma forma importante e fonte de contingência? Violência rompe com as normas ou a violência reforça as normas? Violência é uma situação visível ou a violência é um processo oculto? A violência do Estado é reativa em relação à violência ilegítima ou a violência do Estado é ativa em distinguir violência legítima e ilegítima? Violência é um processo social significativo, cujo sentido é posto em um referente externo ou a violência é um processo social caracterizado, exclusivamente, pela autorreferência? A violência repele ou a violência atrai? A violência é um meio para um fim ou é um fim em si mesmo? (SCHINKEL apud MISSE, 2016, p. 48).

Face à impressionante lista de antinomias, afirma Schinkel (2010, p. 17) que "tanto a definição como a não definição da violência levam-nos a ângulos mortos em resultado dos quais certas formas de violência escapam à percepção". Sendo certo que, por outro lado, como adianta o mesmo autor, essa não percepção representa um mecanismo de invisibilização que, em última análise redunda em formas de aprovação e de legitimação.

\section{A violência e maus-tratos contra os idosos}

As violências contra a pessoa idosa podem assumir variadas formas. Podem ser visíveis ou invisíveis: as visíveis são as mortes e lesões; as invisíveis são aquelas que ocorrem sem machucar o corpo, mas provocam sofrimento, desesperança, depressão e medo (BRASIL, 2014). A maioria dessas últimas, de acordo com Minayo, Figueiredo e Mangas (2017), é incontável.

Segundo a Secretaria dos Direitos Humanos da Presidência da República, têm crescido de forma significativa as denúncias contra as violações dos direitos humanos das pessoas idosas em todo o País. As estatísticas do módulo denominado Disque 100, de forma sistemática aponta esta realidade. Contudo, a denúncia, em si, é apenas uma parte que compõe um elo muito maior. É necessário identificar cada caso, encaminhá-lo a quem de direito, e acima de tudo acompanhar as tratativas para que seu desfecho seja o mais célere e o mais efetivo possível e os idosos terem, senão os seus direitos fundamentais plenamente resguardados, ao menos 
o encaminhamento de suas demandas devidamente tratadas e com respostas efetivas (BRASIL, 2021).

$\mathrm{O}$ entendimento da violência familiar como um problema social é recente. Pesquisas acadêmicas sobre o assunto se difundiram principalmente a partir da década de 1980 (BARNETT; MILLERPERRIN; PERRIN, 1997). Os primeiros estudos que versam sobre a violência às pessoas idosas datam de meados da década de 1970, com a publicação do artigo Granny battered (espancamento de avós) no ano de 1975 (KRUG et al., 2002). Outro momento importante para o estudo dos maustratos contra idosos foi a criação de um periódico dedicado exclusivamente ao tema no ano de 1989, existente até os dias atuais, o Journal of Elder Abuse \& Neglect (BARNETT; MILLER-PERRIN; PERRIN, 1997).

Segundo as autoras Minayo, Figueiredo e Mangas (2017), começou-se a tratar do assunto da violência contra idosos no Brasil apenas nas duas últimas décadas, em razão especialmente de dois fatores: o primeiro em função do aumento da população idosa que, portanto, passou a ser muito mais visualizada; e por outro, em razão do protagonismo e articulação desta população no sentido de lutar em busca da ampliação de seus direitos. Frutos desse engajamento resultaram, por exemplo, na promulgação da Política Nacional do Idoso em 1994, na criação do Estatuto do Idoso em 2003 e, posteriormente, na alteração do artigo $n^{\circ} 19$ do Estatuto do Idoso, que norteia especificamente os caminhos a serem seguidos em caso de ocorrência de violência contra idosos, a Lei $n^{0} 12.461$, de 26 de julho de 2011.

O conceito de violência contra a pessoa idosa adotado no Brasil é o desenvolvido pela OMS, que assim a define:

São ações ou omissões cometidas uma vez ou muitas vezes, prejudicando a integridade física e emocional da pessoa idosa, impedindo o desempenho de seu papel social. A violência acontece como uma quebra de expectativa positiva por parte das pessoas que a cercam, sobretudo dos filhos, dos cônjuges, dos parentes, dos cuidadores, da comunidade e da sociedade em geral (BRASIL, 2014, p. 38).
O conceito de violência contra o idoso conforme o Estatuto do Idoso segue a mesma linha da OMS e é definido como "qualquer ação ou omissão praticada em local público ou privado que lhe cause morte, dano ou sofrimento físico ou psicológico" (Estatuto do Idoso, cap. IV, art. 19, §1). E ainda, "é dever de todos zelar pela dignidade do idoso, colocando-o a salvo de qualquer tratamento desumano, violento, aterrorizante, vexatório ou constrangedor" (Capítulo II, art. 10, § 3).

Em 2014 a Secretaria de Direitos Humanos da Presidência da República, encomendou a produção de um material denominado "Manual de enfrentamento à violência contra a pessoa idosa. É possível prevenir. É necessário superar" (BRASIL, 2014). Este trabalho foi coordenado pela socióloga Maria Cecília de Souza Minayo. Tornou-se um documento oficial que descreve os principais conceitos e tipologias de violência, maus-tratos e abusos sofridos pelos idosos. A tipificação das violências sofridas pelos idosos, segundo o Manual de enfrentamento à violência contra a pessoa idosa (BRASIL, 2014), pode ser resumida em: abuso físico, psicológico, sexual, abandono, negligência, abusos financeiros e autonegligência.

De acordo com o Manual de enfrentamento à violência contra a pessoa idosa (BRASIL, 2014), os abusos físicos constituem a forma de violência mais visível: caracterizam-se por empurrões, tapas, beliscões, agressões com cintos, objetos caseiros e até armas de fogo. Fatos marcantes acompanham a violência física: o local de sua ocorrência e as marcas invisíveis. De acordo com o mesmo manual, são nas próprias residências dos idosos ou nas de seus familiares que ocorre a maior incidência; e quando esta violência não resulta em lesões e traumas aparentes há grande dificuldade em identificála, causando mais dor e sofrimento à vítima.

Já o abuso psicológico refere-se a todas as formas de menosprezo, de desprezo, de preconceito e discriminação que trazem como consequência tristeza, isolamento, solidão, sofrimento mental e a depressão ao idoso. O abuso psicológico pode ocorrer por palavras ou por meio de atitudes e atos cujo sofrimento mental contribui, inclusive, 
para tentativas, ou até mesmo suicídio consumado (MINAYO; SOUZA; PAULA, 2010). A socióloga ainda ressalta que os mais pobres e os dependentes físicos e mentais são os mais vulneráveis a esse tipo de violência.

A violência sexual diz respeito ao ato no jogo que ocorre nas relações hétero ou homossexuais e tem por objetivo estimular o idoso ou utilizar-se dele para obter excitação sexual e práticas eróticas e pornográficas impostas por meio de aliciamento, violência física ou ameaças. Um fato que acompanha a violência sexual é que ela, na maioria das vezes, não ocorre de forma isolada. Geralmente é acompanhada por violência psicológica, física e negligências. Tal situação potencializa as consequências desse tipo de violência, aumentando, inclusive, as probabilidades de tentativas de suicídio (BRASIL, 2014).

Já o abandono, na opinião da mesma autora, é uma das maneiras mais perversas de violência contra a pessoa idosa e apresenta várias facetas. A mais comum e perversa ocorre quando os próprios familiares "expulsam" o idoso de sua própria casa. Muitas vezes colocam-no em cubículos nos fundos da casa, privam-no do convívio familiar e social, e sua casa é destinada a um membro mais jovem da família. De acordo com os autores Alves-Silva, Scorsolini-Comin e Santos (2013), outra forma desse tipo de violência é obrigar o idoso a ser inserido em instituição de longa permanência sem seu consentimento.

A violência patrimonial e financeira diz respeito às disputas de familiares pela posse dos bens ou a ações delituosas cometidas por órgãos públicos e privados em relação às pensões, aposentadorias e outros bens dos idosos. Caracterizam-se geralmente pela tentativa de familiares em violar os direitos dos idosos e o forçarem a assinar procurações com o objetivo de tutela, e assim, apossarem-se de seus bens patrimoniais com o intuito de vendê-los, sem seu conhecimento. Há, contudo, formas cruéis, porém mais sutis desse tipo de violência, como a retirada dos idosos por familiares do espaço físico e social no qual sempre viveram, a retirada do cartão de benefício, especialmente de idosos que possuem um grau maior de dependência, violências praticadas por bancos que fazem empréstimos consignados - às vezes em conluio com familiares - sem que os idosos tenham conhecimento e tenham dado consentimento, e violências causadas pelos planos de saúde ao cobrar taxas de coberturas exorbitantes, são apenas alguns exemplos desse tipo de violência.

Por fim, temos a violência autoinfligida e autonegligência. Neste caso é o próprio idoso que maltrata a si mesmo. São casos em que ele próprio se autonegligencia. Alerta Minayo (2014, p. 44) que "um dos primeiros sinais de autonegligência é a atitude de se isolar, de não sair de casa e de se recusar a tomar banho, de não se alimentar direito e de não tomar os medicamentos, manifestando clara ou indiretamente a vontade de morrer". A autora também chama a atenção para o fato de que atitudes de autodestruição realizadas pelos idosos estão associadas a processos de desvalorização que este sofre, bem como a negligências, abandonos e maus-tratos de que é vítima, evidenciando que as expressões de violência de forma geral não são tomadas de maneira isolada. Geralmente se manifestam de modo cumulativo e devem ser objeto de atenção.

A maior importância relativa da violência social/estrutural presente em relatos dos idosos brasileiros pode estar sinalizando para uma conscientização crescente, ainda incipiente, das questões relacionadas ao processo de envelhecimento populacional no País e à garantia dos direitos dos idosos (PASINATO; CAMARANO; MACHADO, 2006). Estudos recentes apontam o desconhecimento, por parte dos idosos, dos serviços que desenvolvem ações para garantia dos direitos civis e que atuam na repressão aos crimes cometidos contra eles; os idosos que dizem conhecer tais serviços mencionam o descrédito quanto à capacidade de resolutividade (CAMARANO, 2004).

As autoras Pasinato, Camarano e Machado (2006) comentam que, por um lado, a violência contra os idosos se insere nos meandros dos conflitos 
intrafamiliares, muitas vezes invisíveis para a sociedade, e por outro, nas sociedades capitalistas, a própria construção do "ser idoso", que associa idade avançada à obsolescência, se traduz em violência social. Isso coloca a violência como parte de uma questão mais ampla de construção da cidadania em um ambiente democrático.

Ao discutir os avanços e contradições do Estatuto do Idoso (BRASIL, 2003), observa-se que a essência do Estatuto está nas normas gerais que dispõem sobre a "proteção integral" aos idosos. O Estatuto do Idoso lança a ideia de que as pessoas idosas gozam de todos os direitos inerentes à pessoa humana e que o envelhecimento é um direito personalíssimo e a sua proteção um direito social. Contudo, ainda há um vasto caminho a prosseguir. Mas, para que a implementação efetiva do Estatuto do Idoso ocorra, deverá ser pensada em um contexto mais amplo onde se leve em conta a necessidade de mecanismos de proteção social para os vários grupos etários. Não se pode perder de vista o principal amálgama social - a solidariedade - em nenhuma de suas modalidades - intergeracional, familiar e social - ao pensar mecanismos viáveis para a promoção do bem-estar social (PASINATO; CAMARANO; MACHADO, 2006).

O filósofo e historiador italiano Norberto Bobbio (1909-2004) assegura que um dos maiores problemas em relação aos direitos do homem não está em fundamentá-los, mas em protegê-los: sem direitos reconhecidos e protegidos não há democracia e somente existe cidadania quando são reconhecidos os direitos fundamentais do cidadão (BOBBIO, 2004). De outro modo, o sociólogo e filósofo francês Edgar Morin (1921) chama a atenção para o perigo da fragmentação dos saberes que criou especialistas frios, uma tecnociência arrogante e um humanismo desprezado. Morin considera impossível conhecer as partes sem conhecer o todo, tanto quanto conhecer o todo sem conhecer, particularmente, as partes. Esses princípios levam o pensamento para além de um conhecimento fragmentado que, por tornar invisíveis as interações entre um todo e sua parte, anula o complexo e oculta os problemas essenciais.

\section{Considerações finais}

Tratar do assunto da violência e violência contra a pessoa idosa no Brasil reveste-se de total importância, já que o Brasil será um país de velhos daqui a pouco tempo. As estatísticas apontam que os índices de envelhecimento no País estão situados acima das médias mundial e latino-americana. Como também somos um dos países mais populosos do mundo ${ }^{10}$, há a necessidade premente de enfrentar esta problemática e buscar alternativas face ao seu enfrentamento. A violência sofrida pelos idosos é uma violação de um direito humano fundamental. Compreender as razões que estão por trás dessa violência supõe um aprofundamento sobre essas relações sociais e sobre o contexto em que essas relações são produzidas.

A Organização Mundial da Saúde (OMS, 2015) chama a atenção para a urgência de ações integradas que possibilitem melhorar a qualidade de vida das pessoas que envelhecem. Comungamos desta possibilidade, pois ações isoladas têm grandes chances de insucessos. Como país membro da ONU, o Brasil possui hoje um conjunto de leis e dispositivos que se baseiam nas convenções internacionais e que são da maior importância no sentido de propiciar um envelhecimento saudável, ativo e participativo.

Por outro lado, enfrentar esta problemática pode ser mais difícil que pareça. A análise da violência contra o idoso não se resume a um estudo eminentemente criminal. O contexto em que ela se desenvolve possui raízes em outros elementos, tais como falta de estrutura de apoio, conflitos familiares, questões estruturais, pobreza, ineficiência de mecanismos de acesso à justiça e outros. Por isso é

${ }^{10}$ Dos 193 países do mundo, o Brasil é o quinto país mais populoso. O Brasil fica atrás apenas de China, Índia, Estados Unidos e Indonésia. 
necessário que se tenha uma visão mais ampliada, que permita a percepção de que o enfrentamento da violência contra o idoso ultrapassa a análise criminal e exige a aplicação dos princípios que norteiam a política nacional, tal como balizados na Lei no 8.842/1994.

As várias formas de violência sofridas pelos idosos brasileiros constituem práticas sociais de violação de direitos consagrados na Constituição da República de 1988 e no Estatuto do Idoso. Portanto, é necessário resguardar e proteger os direitos dos idosos. Apesar das inúmeras possibilidades e contextos em que se originam, as várias expressões de violência podem ser devidamente tratadas, prevenidas e reduzidas.

Sugere-se, nesse sentido, estratégias de enfrentamento que precisam ser pensadas e postas em prática por instituições como famílias, igrejas, escolas e Estado. Essas estratégias podem ocorrer por meio de encontros sistematizados em grupos, com vistas a assegurar a qualidade reflexiva e o aprofundamento sobre a temática de violência contra os idosos; que sejam ações com lestes multidisciplinares que abarquem a complexidade da temática, sem a reduzir a causas e efeitos; ações com metodologias participativas e ativas, perguntas reflexivas, uso de atividades lúdicas, e ressignificações sobre o lugar e o papel da pessoa idosa. Esses encontros precisam ser avaliados, e nesse âmbito propõe-se que sejam sistematizadas as lições aprendidas entre os grupos que se discute a problemática, de forma a auxiliar na formulação de outras iniciativas, evitando que encontros e discussões sejam iniciados de forma frágil ou simplista.

\section{Referências}

ADORNO, S. A criminalidade urbana violenta: um recorte temático. Revista Brasileira de Informação Bibliográfica em Ciências Sociais, Rio de Janeiro, n. 35, p. 3-242, 1993.

ALCÂNTARA, A. O.; CAMARANO, A. A.; GIACOMIN, K. C. (Org.). Politica nacional do idoso: e novas questões. Rio de Janeiro: Ipea, 2016. https://bit.ly/3xLSBIT. Acesso em: 22 mar. 2019.
ALVES-SILVA, J. D; SCORSOLINI-COMIN, F; SANTOS, M. A. Idosos em instituições de longa permanência: desenvolvimento, condições de vida e saúde. Psicologia: Reflexão e Crítica, Porto Alegre, v. 26, n. 4, p. 820-830, 2013. Disponível em: https:// bit.ly/3gHcEmj. Acesso em: 16 jun. 2021. Doi: https://doi.org/10.1590/S0102-79722013000400023

ARON, R. Les étapes de la pensée sociologique. Paris: Gallimard, 1967.

BARNETT, O.; MILLER-PERRIN, C.L.; PERRIN, R. D. Family violence across the lifespan: an introduction. London: Sage Publications, 1997.

BOBBIO, N. A era dos direitos. Tradução: Carlos Nelson Coutinho. Rio de Janeiro: Elsevier, 2004.

BRASIL. [Constituição (1988)]. Constituição da República Federativa do Brasil. Brasília, DF: Senado Federal, 1988.

BRASIL. Lei $\mathrm{n}^{\circ} 10.741$, de $1^{\circ}$ de outubro de 2003. Dispõe sobre o Estatuto do Idoso e dá outras providências. Diário Oficial da União: Seção 1, Brasília, DF, ano 140, n. 192, p. 1, 3 out. 2003.

BRASIL. Lei $\mathrm{n}^{\circ}$ 12.461, de 26 de julho de 2011. Altera a Lei $\mathrm{n}^{\circ} 10.741$, de $1^{\circ}$ de outubro de 2003, para estabelecer a notificação compulsória dos atos de violência praticados contra o idoso atendido em serviço de saúde. Diário Oficial da União: Seção 1, Brasília, DF, n. 143, p. 2, 27 jul. 2011.

BRASIL. Lei $n^{0} 8.842$, de 04 de janeiro de 1994. Dispõe sobre a política nacional do idoso, cria o Conselho Nacional do Idoso e dá outras providências. Diário Oficial da União: Seção 1, Brasília, DF, ano 132, n. 3, p. 77, 5 jan. 1994.

BRASIL. Secretaria de Direitos Humanos da Presidência da República. Respeito: Direito da Pessoa Idosa. Responsabilidade de todos. Brasília: SDH, 2013.

BRASIL. Secretaria de Direitos Humanos da Presidência da República. Brasil: manual de enfrentamento à violência contra a pessoa idosa. É possível prevenir. É necessário superar. Brasília: SDH, 2014.

BRASIL. Secretaria de Direitos Humanos da Presidência da República. Estatísticas do disque 100 (2013, 2014, 2018). Disponível em: https://bit. ly/3gLcMjd. Acesso em: 16 jun. 2021. 
BRETAS, M. L. O crime na historiografia brasileira: uma revisão na pesquisa recente. Revista Brasileira de Informação Bibliográfica em Ciências Sociais, Rio de Janeiro, n. 32, p. 49-61, 1991.

CAMARANO, A. A. Os novos idosos brasileiros: muito além dos 60. Rio de Janeiro: IPEA, 2004.

CAMARGOS, M. C. S.; GONZAGA, M. R.; COSTA, J. V.; BOMFIM, W. C. Estimativas de expectativa de vida livre de incapacidade funcional para Brasil e Grandes Regiões, 1998 e 2013. Ciência \& Saúde Coletiva, Rio de Janeiro, v. 24, n. 3, p. 737-747, mar. 2019. Disponível em: https://bit. ly/3gQW6Hn. Acesso em: 16 jun. 2021. Doi: https:// doi.org/10.1590/1413-81232018243.07612017

CELADE - CENTRO LATINOAMERICANO Y CARIBEÑO DE DEMOGRAFÍA. La nueva era demográfica en América Latina y el Caribe: la hora de la igualdad según el reloj poblacional. Santiago: Cepal, 2014. (Documento Referencia). Disponible en: https://bit.ly/3iUVVNR. Acceso en: 5 abr. 2019.

CEPAL - COMISIÓN ECONÓMICA PARA AMÉRICA LATINA Y EL CARIBE. O futuro do envelhecimento no Brasil: datas emblemáticas e opções de política: perspectivas para 2014 e mais adiante. Santiago: Cepal, 2013. (Serie Futuro del Envejecimiento; 2). Disponível em https://bit. ly/3iZRilt. Acesso em: 5 abr. 2019.

CEPAL - COMISIÓN ECONÓMICA PARA AMÉRICA LATINA Y EL CARIBE. Panorama social de América Latina 2017. Santiago: Cepal, 2018. Disponível em: https://bit.ly/35G0bbX. Acesso em 20 abr. 2021.

ELIAS, N. Conocimiento y poder. Madrid: La Piqueta, 1994.

ELIAS, N. O processo civilizador: formação do Estado e civilização. Rio de Janeiro: Jorge Zahar, 1993. v. 2.

ELIAS, N. O processo civilizador: uma história dos costumes. Rio de Janeiro: Jorge Zahar, 1990. v. 1.

FOUCAULT, M. Microfisica do poder. Organização e tradução: Roberto Machado. Rio de Janeiro: Edições Graal, 1979.
HOBBES, T. Leviatã ou matéria forma e poder de um Estado eclesiástico e civil. Tradução: João Paulo Monteiro e Maria Nizza da Silva. São Paulo: Martins Fontes, 2003.

IBGE. Sintese de indicadores sociais: uma análise das condições de vida da população brasileira. Rio de Janeiro: IBGE, 2017.

KRUG, E. G.; DAHLBERG, L. L; MERCY, J. A.; ZWI, A. B.; LOZANO, R. World report on violence and health. Geneva: WHO, 2002.

LIMA, R. K.; MISSE, M.; MIRANDA, A. P. M. Violência, criminalidade, segurança pública e justiça criminal no Brasil: uma bibliografia. Revista Brasileira de Informação Bibliográfica em Ciências Sociais, Rio de Janeiro, n. 50, p. 45-123, jul./ ago. 2000 .

LIMA, T. C. S.; MIOTO, R. C. T. Procedimentos metodológicos na construção do conhecimento científico: a pesquisa bibliográfica. Revista Katálysis, Florianópolis, v. 10, p. 37-45, 2007. Número especial. Disponível em: https://bit.ly/3wKDQ9g. Acesso em: 22 mar. 2019. Doi: https://doi. org/10.1590/S1414-49802007000300004

MINAYO, M. C. S.; FIGUEIREDO, A. E. B.; MANGAS, R. M. N. O comportamento suicida de idosos institucionalizados: histórias de vida. Physis, Rio de Janeiro, v. 27, n. 4, p. 981-1002, dez. 2017.

MINAYO, M. C. S.; SOUZA, E. R.; PAULA, D. R. Revisão sistemática da produção acadêmica brasileira sobre causas externas e violências contra a pessoa idosa. Ciência \& Saúde Coletiva, Rio de Janeiro, v. 15, n. 6, p. 2709-2718, 2010.

MISSE, M. Violência e teoria social. Dilemas: Revista de Estudos de Conflito e Controle Social, Rio de Janeiro, v. 9, n. 1, p. 45-63, jan. 2016. Disponível em: https://bit.ly/35Mo3uJ. Acesso em: 6 abr. 2019.

MISSE, M.; SILVA, L. A. M.; LEITE, M. P.; VÉRAN, J-F; VARGAS, J. D.; WERNECK, A. Violência, sujeito e sociologia: entrevista com Michel Wieviorka. Dilemas: Revista de Estudos de Conflito e Controle Social, Rio de Janeiro, v. 2, n. 3, p. 143-172, jan. 2009. Disponível em: https://bit. ly/3gTbOl7. Acesso em: 22 mar. 2019. 
MORIN, E. A cabeça bem-feita: repensar a reforma, reformar o pensamento. 18. ed. Rio de Janeiro: Bertrand Brasil, 2010.

ODÁliA, N. O que é a violência. São Paulo: Brasiliense, 2017. (Coleção Primeiros Passos).

OMS - ORGANIZAÇÃO MUNDIAL DA SAÚDE. Relatório Mundial de Envelhecimento e Saúde. Genebra: OMS, 2015. Disponível em: https://bit. ly/3gR1OKs. Acesso em: 16 jun. 2021.

OMS - ORGANIZAÇÃO MUNDIAL DA SAÚDE. Resolução ONU no 217-A de 10 de dezembro de 1948. Diário Oficial da União, 11 dez. 1948. Disponível em: https://bit.ly/3d0oRzW. Acesso em 4 abr. 2019.

ONU - ORGANIZAÇÃO DAS NAÇÕES UNIDAS. Uma sociedade para todas as idades: ano internacional dos idosos. Genebra: ONU, 1999.

PASINATO, M. T,; CAMARANO, A. A.; MACHADO, L. Idosos vítimas de maus-tratos domésticos: estudo exploratório das informações levantadas nos serviços de denúncia. Rio de Janeiro: IPEA, 2006. (Textos para Discussão; 1200).

PNUD - PROGRAMA DAS NAÇOES UNIDAS PARA O DESENVOLVIMENTO. Relatório anual Brasil: 2017. Brasília: PNDU, 2018. Disponível em: https://bit.ly/2SYGV6V. Acesso em: 3 abr. 2021.

SALLAS, A. L. F. Resenhas. Campos: Revista de Antropologia Social, Curitiba, v. 1, p. 217-22, 2001. Resenha da obra: ELIAS, Norbert; SCOTSON, John L. Os estabelecidos e os outsiders: sociologia das relações de poder a partir de uma pequena comunidade. Rio de Janeiro: Jorge Zahar, 2000. Disponível em: https://bit.ly/3zT5HFZ. Acesso em: 26 mar. 2019.

SANTOS, J. V. T. Violências e dilemas do controle social nas sociedades da "modernidade tardia". São Paulo em Perspectiva, São Paulo, v. 18, n. 1, p. 3-12, mar. 2004.

SCHINKEL, W. Aspects of violence: a critical theory. New York: Palgrave Macmillian, 2010.

SOUSA LOPES, E. D.; DELBOUX, M. J. Violência contra a pessoa idosa no município de Campinas, São Paulo, nos últimos 11 anos: uma análise temporal. Revista Brasileira de Geriatria e Gerontologia, Rio de Janeiro, v. 24, n. 6, p. e200320, 2021.

SOUSA, R. C. R.; ARAÚJO, G. K. N.; SOUTO, R. Q.; SANTOS, R. C.; SANTOS, R. C.; ALMEIDA, L. R. Fatores associados ao risco de violência contra mulheres idosas: um estudo transversal. Revista Latino-Americana de Enfermagem, Ribeirão Preto, v. 29, e3394, 2021. Disponível em: https://bit. ly/3zPz1NR. Acesso em: 20 abr. 2021. Doi: https:// doi.org/10.1590/1518-8345.4039.3394

SPOSITO, M. P. Um breve balanço da pesquisa sobre violência escolar no Brasil. Educação e Pesquisa, São Paulo, v. 27, n. 1, p. 87-103, 2001. Disponível em: https://bit.ly/3wTb86b. Acesso em: 20 mar. 2019. Doi: http://dx.doi.org/10.1590/ S1517-97022001000100007

WEBER, M. Economia e sociedade: fundamentos da sociologia compreensiva. Brasília: Ed. UnB, 1991. v. 1.

WIEVIORKA, M. Violência: entrevista de Michel Wieviorka . Mexico: [s. n.], 9 maio 2018. 1 vídeo (6 min). Publicada pelo canal do Institut français d'Amérique latine. Disponível em: https://bit. ly/2U07cSk. Acesso em: 3 abr. 2019.

ZALUAR, A. Violência e crime. In: MICELI, S. (Org.). O que ler na ciência social brasileira (19701995). São Paulo: Anpocs, 1999. v. 1, p. 13-107.
Recebido em: 13 nov. 2020 Aceito em: 18 jun. 2021 
Meleiro, M. L. A. P.; Nascimento, I. R.; Neves, A. L. M. 